\title{
Antegrade or retrograde approach for thoracic duct embolization? Inhalation may be part of the answer
}

\author{
Gérald Gahide $1^{1^{*}}$ and Karl Sam ${ }^{2}$
}

To the Editor,

We read with great interest the nice case reported by Rott et al. regarding their successful transvenous retrograde thoracic duct embolization (Rott and Boecker 2020). This is a very interesting and promising technique that should probably be considered and used more often. The authors reported some difficulties in navigating the thoracic duct due to its small caliber. We were wondering if they had used any dynamic maneuver to try to open the thoracic duct valves.

A patient was recently referred to our department for the treatment of a high-outpout chylothorax following a right lower lobectomy. After a lengthy and unsuccessful attempt of intranodal lymphangiography, it was decided to try a transvenous retrograde thoracic duct embolization. After localizing the thoracic duct with a left subclavian venography, a retrograde catheterization of the thoracic duct was performed using a 0.021in microcatheter over a glidewire. As Rott et al., we faced several points of resistance when trying to navigate the thoracic duct. Koike et al. suggested that the process of advancing the wire and the catheter in the duct is extensive, especially because of the difficulty in traversing the terminal valves (Koike et al. 2013). We then hypothesized that a negative thoracic pressure induced by inhalation could open the thoracic duct valves as it does with the venous system. Whenever a point of resistance was faced, the patient was asked to take a deep breath. This technique greatly helped the progression of the microcatheter till the cysterna chyli, that was reached in a matter of minutes.

\footnotetext{
* Correspondence: Geraldgahide@hotmail.com

'Service d'Angioradiologie, Département d'Imagerie Médicale, Centre Hospitalier Universitaire de Sherbrooke, 3001, 12ème avenue Nord,

Sherbrooke, Québec J1H 5H3, Canada

Full list of author information is available at the end of the article
}

If we were to treat a thoracic duct injury again, it is very likely that we would try a retrograde catheterization first. Though many publications have reported impressive results when performing an intranodal lymphography, our short experience was not that enjoyable. We encountered three main difficulties. First, we didn't have the chance to use a dedicated syringe to infuse the Lipiodol (Guerbet, France), making the delicate and constant infusion very difficult. Secondly, the $25 \mathrm{G}$ needle placed at the corticomedullary interface of the node was very instable, and we lost several beautiful lymphatic channels. Last, we had some lipiodol going directly into the internal iliac venous system due a chylovenous communication that made us stop because of the uncertainty relating to its significance. According to Kariya et al., $76.9 \%$ of the patients have a simple cervical thoracic duct, meaning a catheterizable thoracic duct, the remaining of patients having a plexiform anatomy (Kariya et al. 2018). Considering all the hurdles of the lymphography, not to speak of the rate of success for the subsequent percutaneous transabdominal cysterna chyli catheterization, it makes no doubt that it is really worth trying a retrograde approach first. In this regard, we are also interested in knowing if the authors have any recommendation regarding how to localize the thoracic duct.

Sincerely yours,

Gerald Gahide and Karl Sam.

\section{Acknowledgements}

N/A

\section{Authors' contributions}

All the authors made significant contribution to this manuscript. GG and KS wrote and revised the manuscript. Both authors read and approved the final manuscript.

\section{Funding}

N/A

\section{Springer Open}

(0) The Author(s). 2020 Open Access This article is licensed under a Creative Commons Attribution 4.0 International License, which permits use, sharing, adaptation, distribution and reproduction in any medium or format, as long as you give appropriate credit to the original author(s) and the source, provide a link to the Creative Commons licence, and indicate if changes were made. The images or other third party material in this article are included in the article's Creative Commons licence, unless indicated otherwise in a credit line to the material. If material is not included in the article's Creative Commons licence and your intended use is not permitted by statutory regulation or exceeds the permitted use, you will need to obtain permission directly from the copyright holder. To view a copy of this licence, visit http://creativecommons.org/licenses/by/4.0/. 


\section{Availability of data and materials}

N/A

Ethics approval and consent to participate

N/A

Consent for publication

N/A

\section{Competing interests}

The authors declare not to have any competing interest regarding this manuscript.

\section{Author details}

'Service d'Angioradiologie, Département d'Imagerie Médicale, Centre Hospitalier Universitaire de Sherbrooke, 3001, 12ème avenue Nord, Sherbrooke, Québec J1H 5H3, Canada. ${ }^{2}$ Département de Radiologie, Centre Hospitalier Universitaire de Trois Rivières, 1991 Boulevard du Carmel,

Trois-Rivières, QC G8Z 3R9, Canada.

Received: 1 July 2020 Accepted: 10 July 2020

Published online: 15 July 2020

\section{References}

Kariya S, Nakatani M, Ueno Y, Yoshida A, Ono Y, Maruyama T et al (2018) Transvenous retrograde thoracic Ductography: initial experience with 13 consecutive cases. Cardiovasc Intervent Radiol 41:406-414. https://doi.org/10. 1007/s00270-017-1814-y

Koike Y, Hirai C, Nishimura J, Moriya N, Katsumata Y (2013) Percutaneous transvenous embolization of the thoracic duct in the treatment of chylothorax in two patients. J Vasc Interv Radiol 24:135-137. https://doi.org/ 10.1016/j.jvir.2012.10.005

Rott G, Boecker F (2020) High-output chyloperitoneum following laparoscopic Nissen fundoplication treated with retrograde transvenous thoracic duct embolization. CVIR Endovasc 3:20. https://doi.org/10.1186/s42155-020-00110-9

\section{Publisher's Note}

Springer Nature remains neutral with regard to jurisdictional claims in published maps and institutional affiliations.

\section{Submit your manuscript to a SpringerOpen ${ }^{\circ}$ journal and benefit from:}

- Convenient online submission

- Rigorous peer review

- Open access: articles freely available online

High visibility within the field

- Retaining the copyright to your article 